\title{
Improving the efficiency of organic photovoltaic cells by introducing an ultrathin modification layer with a strong dipole moment
}

\author{
FU GuangSheng ${ }^{1}$, KONG WeiGuang ${ }^{1}$, HAN LingJie ${ }^{1}$, YANG QiMan $^{1}$, HOU LiXin $^{2}$ \& \\ YANG ShaoPeng ${ }^{1 *}$ \\ ${ }^{1}$ College of Physics Science and Technology, Hebei University, Baoding 071002, China; \\ ${ }^{2}$ China Lucky Film Corporation, Baoding 071054, China
}

Received October 9, 2011; accepted December 12, 2011

\begin{abstract}
A method to improve the efficiency of organic photovoltaic cells through inclusion of an ultrathin modification layer of $\mathrm{Al}_{2} \mathrm{O}_{3}$ or $\mathrm{LiF}$ sandwiched between poly(3,4-ethylenedioxythiophene)-polystyrene sulfonic acid (PEDOT:PSS) and indium tin oxide layers is developed. Because of the strong dipole moments of $\mathrm{LiF}$ and $\mathrm{Al}_{2} \mathrm{O}_{3}$, either can enhance the built-in electric field, which increases the probability of the carriers reaching the corresponding electrode. In addition, the low work function of PEDOT:PSS can decrease the energy barrier for carrier transmission. A $21.7 \%$ improvement in the power conversion efficiency of experimental devices was achieved, mainly because the short circuit current was enhanced by almost $30 \%$.
\end{abstract}

solar cell, modification layer, work function, photovoltaics

Citation: Fu G S, Kong W G, Han L J, et al. Improving the efficiency of organic photovoltaic cells by introducing an ultrathin modification layer with a strong dipole moment. Chin Sci Bull, 2012, 57: 1655-1658, doi: 10.1007/s11434-012-5098-y

Organic photovoltaic (OPV) devices have attracted tremendous interest because of their inherent advantages including low cost, large area, light weight and flexibility. The power conversion efficiency (PCE) of such devices has been reported to reach $6 \%-7 \%[1,2]$. However, the efficiency of polymer solar cells is still lower than what is needed for practical application on a large scale. Besides significant effort focused on the bulk heterojunction (BHJ) photoactive layer, the properties of the interfaces between the photoactive layer and electrode or underlying buffer layer, e.g., Ohmic contact, interfacial cohesion, or charge traps, are of fundamental importance to the performance of OPV devices. This is because they can significantly affect the charge transport and collection processes as well as the built-in potential [3]. Therefore, control of these interfaces is essential to improve the PCE of OPV cells.

Poly(3,4-ethylenedioxythiophene)-polystyrene sulfonic acid (PEDOT:PSS) is one of the most popular anode modification materials because it can effectively improve the inter-

*Corresponding author (email: spyang@hbu.edu.cn) face between indium tin oxide (ITO) and the photoactive layer, significantly enhancing both the short-circuit current $\left(J_{\text {sc }}\right)$ and the fill factor $(\mathrm{FF})$. However, the ITO/PEDOT:PSS interface is not stable and chemical reactions finally result in degradation of the device performance [4]. Recently, Yoon et al. [5] introduced a plasma-oxidized silver layer with a thickness of $1 \mathrm{~nm}$ on top of ITO in poly(3-hexylthiophene) (P3HT) and phenyl-C61-butyric acid methyl ester (PCBM)-based BHJ solar cells, and improvements in $J_{\text {sc }}$ and PCE of nearly $17.6 \%$ and $9.1 \%$, respectively, were achieved. In this article, $\mathrm{Al}_{2} \mathrm{O}_{3}$ and $\mathrm{LiF}$ layers with a thickness of $1 \mathrm{~nm}$ are used to modify the interface between ITO and PEDOT:PSS. $\mathrm{Al}_{2} \mathrm{O}_{3}$ and $\mathrm{LiF}$ possess strong dipole moments, which can lower the work function (WF) of the anode, enhancing the built-in electric field and decreasing the energy barrier for charge carrier transmission to significantly improve both $J_{\mathrm{sc}}$ and PCE.

\section{Experimental}

PEDOT:PSS, P3HT and PCBM were purchased from Lu- 
minescence Technology Corporation. A $1 \mathrm{~nm}$-thick layer of $\mathrm{Al}_{2} \mathrm{O}_{3}$ was formed on a clean ITO-coated substrate by the following two steps. First, a $1 \mathrm{~nm}$-thick Al film was thermally evaporated on the ITO surface at $1.0 \times 10^{-3} \mathrm{~Pa}$. Second, the $\mathrm{Al}$ film, which actually oxidized to $\mathrm{AlO}_{x}$, was oxidized in air at $150^{\circ} \mathrm{C}$ for more than $1 \mathrm{~h}$ to form $\mathrm{Al}_{2} \mathrm{O}_{3}$. In contrast, the LiF layer was directly formed on the ITO substrate by thermal evaporation at $3.4 \times 10^{-4} \mathrm{~Pa}$. A film thickness detector (Taiyao Vacuum Technology FTM-V) was used to monitor the evaporation process, and the final thickness was determined by a profilometer (Veeco Dektak 150).

The anode substrate was prepared by spin-casting a thin layer of PEDOT:PSS on the $\mathrm{Al}_{2} \mathrm{O}_{3}$ or LiF-coated ITO surface. This was followed by spin-casting of the active layer of P3HT:PCBM (dissolved in chloroform with a weight ratio of $1: 1,20 \mathrm{mg} / \mathrm{mL}$ ). $\mathrm{LiF}$ and $\mathrm{Al}$ cathodes were then deposited via thermal evaporation through a shadow mask at $3.4 \times 10^{-4} \mathrm{~Pa}$, giving an active device area of $0.16 \mathrm{~cm}^{2}$. Finally, thermal annealing was performed at $130^{\circ} \mathrm{C}$ for $5 \mathrm{~min}$. The final structure of the experimental cells was $\mathrm{ITO} / \mathrm{LiF}$ (or $\left.\mathrm{Al}_{2} \mathrm{O}_{3}, 1 \mathrm{~nm}\right) / \mathrm{PEDOT}: \mathrm{PSS}(35 \pm 3 \mathrm{~nm}) / \mathrm{P} 3 \mathrm{HT}: \mathrm{PCBM}(130 \pm$ $5 \mathrm{~nm}) / \mathrm{Al}(100 \mathrm{~nm})$.

In our experiments, control devices with the structure ITO/ PEDOT:PSS( $35 \pm 3 \mathrm{~nm}) / \mathrm{P} 3 \mathrm{HT}: \mathrm{PCBM}(130 \pm 5 \mathrm{~nm}) / \mathrm{Al}(100 \mathrm{~nm})$ were also fabricated and tested. To minimize variation in the results that might arise due to different processing conditions, OPVs with different anode structures were fabricated in the same batch.

\section{Results and discussion}

Figure 1 shows the current density-voltage $(J-V)$ characteristics of the OPVs with ITO anodes with different surface modifications under AM 1.5 G filtered illumination from a calibrated solar simulator with an overall intensity of 100 $\mathrm{mW} / \mathrm{cm}^{2}$. The extracted device parameters are summarized in Table 1. The control cell exhibits a PCE of $2.76 \%$ with a relatively high $\mathrm{FF}$ of $51.6 \%$. The open circuit voltage $\left(V_{\text {oc }}\right)$ and $J_{\mathrm{sc}}$ are $0.60 \mathrm{~V}$ and $8.89 \mathrm{~mA} / \mathrm{cm}^{2}$, respectively. The $J-V$ curves of the cells containing $\mathrm{Al}_{2} \mathrm{O}_{3}$ and $\mathrm{LiF}$ layers almost overlap, and an evident enhancement in $J_{\mathrm{sc}}$ is observed compared to the control cell. For the LiF-modified cell, $J_{\mathrm{sc}}$ is improved by $27 \%$ from 8.89 to $11.3 \mathrm{~mA} / \mathrm{cm}^{2}$. In contrast, the $\mathrm{Al}_{2} \mathrm{O}_{3}$-modified cell exhibits a $29 \%$ enhancement in $J_{\text {sc }}$ from 8.89 to $11.5 \mathrm{~mA} / \mathrm{cm}^{2}$. Both cells enhance the PCE by $21.7 \%$ from $2.76 \%$ to $3.36 \%$. However, both $\mathrm{Al}_{2} \mathrm{O}_{3}$ and $\mathrm{LiF}$ lead to a decreased FF. Because $\mathrm{Al}_{2} \mathrm{O}_{3}$ and $\mathrm{LiF}$ both have a high resistance, this phenomenon can be explained by the higher series resistance of the OPV cells containing an additional layer. It also can be seen that the $V_{\mathrm{oc}}$ of the cells is almost the same $(\sim 0.6 \mathrm{~V})$. This is because $V_{\text {oc }}$ is primarily determined by the difference in WF between the lowest unoccupied molecular orbital (LUMO) of the acceptor and highest occupied molecular orbital (HOMO) of the donor

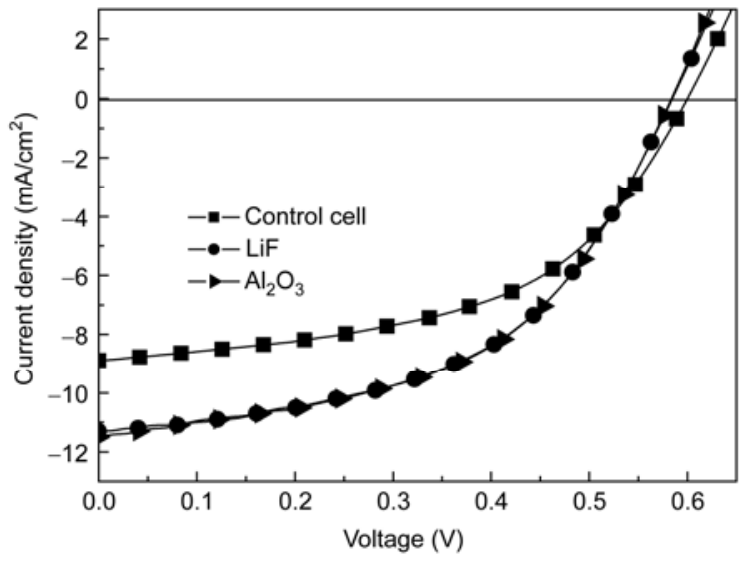

Figure $1 J$ - $V$ characteristics of OPV devices containing different anodic modifications under illumination.

Table 1 Performance parameters of OPV cells with different anode structures

\begin{tabular}{lcccc}
\hline & $J_{\mathrm{sc}}\left(\mathrm{mA} / \mathrm{cm}^{2}\right)$ & $V_{\mathrm{oc}}(\mathrm{V})$ & $\mathrm{FF}(\%)$ & PCE $(\%)$ \\
\hline Control cell & 8.89 & 0.60 & 51.6 & 2.76 \\
ITO/LiF/PEDOT:PSS & 11.3 & 0.58 & 51.2 & 3.36 \\
ITO/Al $\mathrm{O}_{3} /$ PEDOT:PSS & 11.5 & 0.58 & 50.4 & 3.36 \\
\hline
\end{tabular}

[6,7], and consequently the influence of the electrode WF on $V_{\text {oc }}$ is negligible [8].

Figure 2 shows the effects of modification layers of different thickness on the performance of the OPV cells. As mentioned above, $\mathrm{LiF}$ and $\mathrm{Al}_{2} \mathrm{O}_{3}$ exhibits similar features as an anodic modification layer, so here we only discuss $\mathrm{Al}_{2} \mathrm{O}_{3}$. Figure 2 shows that there is an obvious deterioration in the performance of the OPV cells as the thickness of the $\mathrm{Al}_{2} \mathrm{O}_{3}$ layer is increased from 1 to $5 \mathrm{~nm}$. The optimal thickness of $\mathrm{Al}_{2} \mathrm{O}_{3}$ is expected to be $1 \mathrm{~nm}$. As the thickness of $\mathrm{Al}_{2} \mathrm{O}_{3}$ increases, $V_{\mathrm{oc}}$ decreases slightly compared to $J_{\mathrm{sc}}$, which drops sharply from 11.5 to $5.33 \mathrm{~mA} / \mathrm{cm}^{2}$ because of the

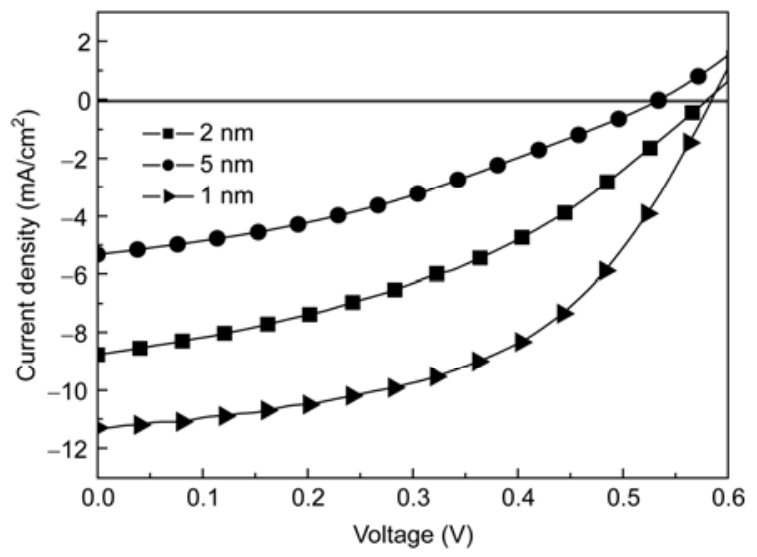

Figure $2 J-V$ characteristics plotted to illustrate the effects of different thicknesses of $\mathrm{Al}_{2} \mathrm{O}_{3}$ on the photovoltaic performance of the experimental cells. 
strong insulating character of $\mathrm{Al}_{2} \mathrm{O}_{3}$ [9]. In addition, because the $\mathrm{Al}_{2} \mathrm{O}_{3}$ layer is oxidized from $\mathrm{Al}$, any unoxidized $\mathrm{Al}$ will force the OPV cell to invert, causing the performance of the OPV cell to deteriorate abruptly.

To clarify the origin of the enhancement in $J_{\mathrm{sc}}$ in the experimental solar cells, optical transmission spectra for the experimental and control cells without an $\mathrm{Al}$ electrode were measured from 300 to $800 \mathrm{~nm}$ by an ultraviolet-visibleinfrared spectrometer. As illustrated in Figure 3, the transmission spectra for the experimental and control cells are very similar with only a slight difference at around $400 \mathrm{~nm}$. This small difference could not cause the almost $30 \%$ enhancement in current observed in our experiment. Moreover, the coverage of the modification layer on ITO is very low with the formation of small islands, so optical-field redistribution is unlikely to explain the enhancement in $J_{\mathrm{sc}}$. Therefore, reason for the improvement in $J_{\text {sc }}$ is increased efficiency of carrier collection at the electrode.

Figure 4 shows the energy band diagram for the experimental OPV cells, which provides evidence for a possible mechanism for the influence of $\mathrm{Al}_{2} \mathrm{O}_{3}$ and $\mathrm{LiF}$ layers on the cell performance. Because of the strong dipole moment of $\mathrm{Al}_{2} \mathrm{O}_{3}$ and $\mathrm{LiF}$, even a monolayer of these materials will induce a mass of interfacial dipoles that can lower the WF of PEDOT:PSS, which really functions as the anode. On the one hand, the lowered WF of PEDOT:PSS so it approaches the HOMO of the donor material can help hole carriers to transfer to the anode more easily because the energy barrier is decreased [5]. On the other hand, it can effectively enhance the built-in electric field of the OPV cells $[9,10]$. This is because the built-in electric field is primarily determined by the difference in WF between the anode and cathode materials when the thickness of the photoactive layer is the same. In addition, the chemical structure at the interfaces between the $\mathrm{Al}$ cathode and the photoactive layer may cause the WF of $\mathrm{Al}$ to be larger than $4.2 \mathrm{eV}$ because of the formation of $\mathrm{Al}-\mathrm{O}$ bonds at $\mathrm{Al} /$ polymer interface caused by post-annealing [11]. Therefore, the built-in electric field in a

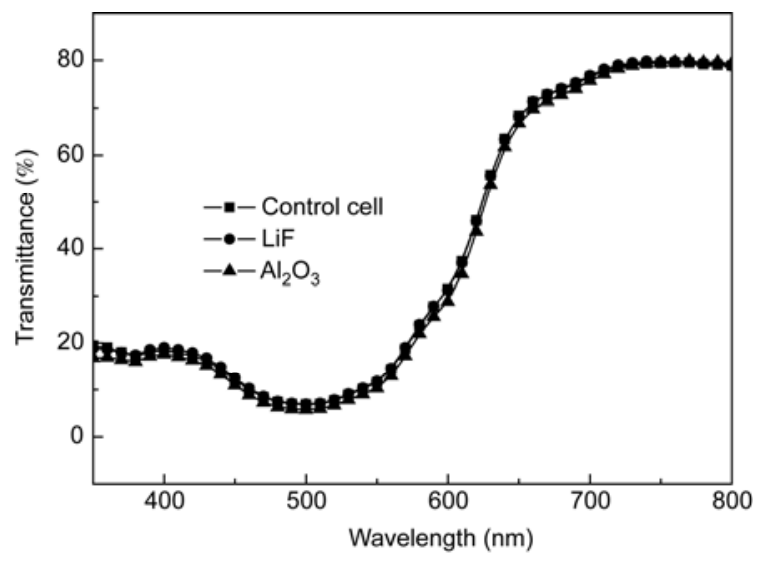

Figure 3 Transmission spectra of experimental and control cells without an $\mathrm{Al}$ electrode.

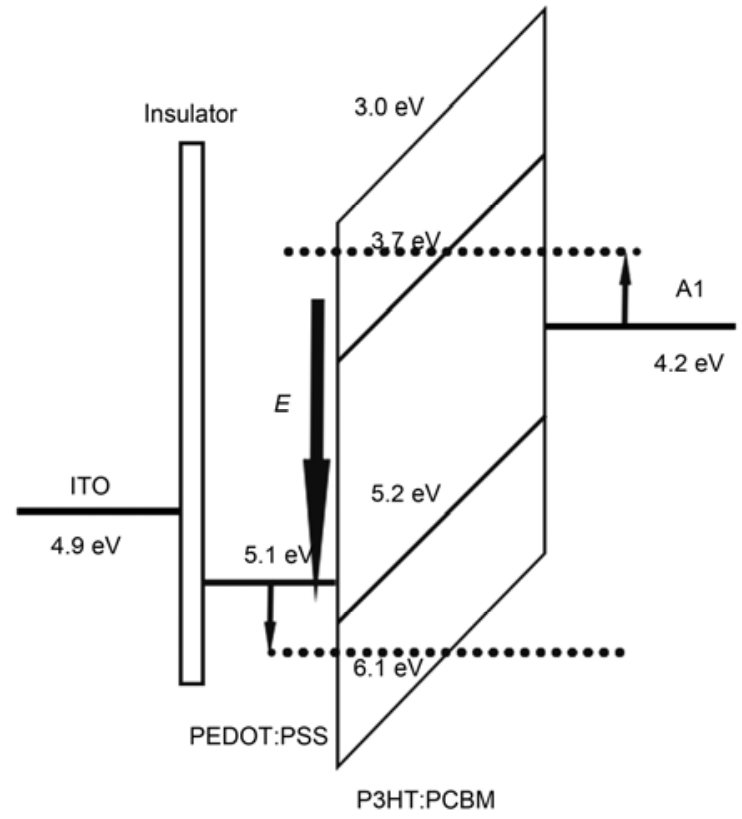

Figure 4 Energy band diagram for the experimental OPV cells.

device can be improved by addition of a thin layer of a material with a strong dipole moment.

In the P3HT:PCBM blended layer, carriers may recombine if the transport time is longer than the carrier lifetime. The built-in electric field, which is directed from the cathode towards the anode, is the driving force for holes and electrons moving towards each corresponding electrode. Thus, a larger internal electric field can help charge carriers reach to each electrode in a shorter time, which eventually generates a higher efficiency of charge carrier collection. As a consequence, both $J_{\mathrm{sc}}$ and PCE are obviously improved.

\section{Conclusion}

In summary, a method to modify the interface between PEDOT:PSS and the anode was developed because this interface is not stable, which can result in degradation of device performance. An obvious improvement in PCE for OPV devices was achieved, mainly because of an enhanced $J_{\text {sc }}$, by using a thin film of $\mathrm{Al}_{2} \mathrm{O}_{3}$ or LiF between ITO and PEDOT:PSS. Both LiF and $\mathrm{Al}_{2} \mathrm{O}_{3}$ possess a strong dipole moment, so an enhanced built-in electric field is expected to be the main reason for the improved $J_{\mathrm{sc}}$. Furthermore, the decreased energy barrier between the anode and HOMO of the donor material can also increase $J_{\text {sc }}$. Our results match well with the belief that $V_{\mathrm{oc}}$ is primarily determined by the offset between the LUMO of the acceptor and HOMO of the donor in OPV cells.

This work was supported by the Natural Science Foundation of Hebei Province (F20010000306) and the Science Research Program of Hebei Education Department of China. 
1 Park S H, Roy A, Beaupre S, et al. Bulk heterojunction solar cells with internal quantum efficiency approaching $100 \%$. Nat Photonics, 2009, 3: 297-302

2 Chen H Y, Hou J, Zhang S, et al. Polymer solar cells with enhanced open-circuit voltage and efficiency. Nat Photonics, 2009, 3: 649-653

$3 \mathrm{Xu} \mathrm{Z} \mathrm{Q,} \mathrm{Li} \mathrm{J,Yang} \mathrm{J} \mathrm{P,} \mathrm{et} \mathrm{al.} \mathrm{Enhanced} \mathrm{performance} \mathrm{in} \mathrm{polymer} \mathrm{pho-}$ tovoltaic cells with chloroform treated indium tin oxide anode modification. Appl Phys Lett, 2011, 98: 253303

4 de Jong M P, van IJzendoorn L J, de Voigt M J A. Stability of the interface between indium-tin-oxide and poly(3,4-ethylenedioxythiophene)/ poly(styrenesulfonate) in polymer light-emitting diodes. Appl Phys Lett, 2000, 77: 2255-2257

5 Yoon W J, Berger P R. 4.8\% efficient poly (3-hexylthiophene)-fullerene derivative (1:0.8) bulk heterojunction photovoltaic devices with plasma treated $\mathrm{AgOx} /$ indium tin oxide anode modification. Appl Phys Lett, 2008, 92: 013306

6 Scharber M C, Mühlbacher D, Koppe M, et al. Design rules for do- nors in bulk-heterojunction solar cells-Towards 10\% energy-conversion efficiency. Adv Mater, 2006, 18: 789-794

7 Rand B P, Burk D P, Forrest S R. Offset energies at organic semiconductor heterojunctions and their influence on the open-circuit voltage of thin-film solar cells. Phys Rev B, 2007, 75: 115327

$8 \mathrm{Li} \mathrm{L} \mathrm{G,} \mathrm{Lu} \mathrm{G} \mathrm{H,} \mathrm{Yang} \mathrm{X} \mathrm{N,} \mathrm{et} \mathrm{al.} \mathrm{Progress} \mathrm{in} \mathrm{polymer} \mathrm{solar} \mathrm{cell.} \mathrm{Chin}$ Sci Bull, 2007, 52: 145-158

9 Tsai H W, Pei Z, Chan Y J. A conductor/insulator/conductor complex layer at anode for current enhancement in a polymer solar cell. Appl Phys Lett, 2008, 93: 073310

10 Brabec C J, Shaheen S E, Winder C, et al. Effect of LiF/metal electrodes on the performance of plastic solar cells. Appl Phys Lett, 2000, 80: 1288-1290

11 Crispin A, Jonsson A, Fahlman M, et al. Aluminum-barium interfaces on some processable poly( $p$-phenylenev-inylene) polymers studied by photoelectron spectroscopy. J Chem Phys, 2001, 115: 52525257

Open Access This article is distributed under the terms of the Creative Commons Attribution License which permits any use, distribution, and reproduction in any medium, provided the original author(s) and source are credited. 